\title{
Red Cell Survival Studies in Hereditary Spherocytosis
}

\author{
JAMES S. WIIEY \\ From the Department of Medicine, University of Sydney, 2006, New South \\ Wales, and Clinical Research Unit, Royal Prince Alfred Hospital, \\ Australia
}

\begin{abstract}
A в STRACT The in vivo survival of hereditary spherocytes has been investigated with the ${ }^{\text {B1 }} \mathrm{Cr}$ red cell survival technique. Spherocytes invariably showed a shorter survival in a normal recipient than in the donor's own circulation. Moreover transfusion of spherocytes from a mother to her son, both with hereditary spherocytosis, showed that "foreign" spherocytes have a shorter survival than the "self" spherocytes of the recipient. These findings are attributed to splenic reticuloendothelial blockade, specific towards hereditary spherocytes in the patient's own circulation. There was no correlation between the $\mathrm{Na}^{+}$influx and the hemolytic tendency of hereditary spherocytes when the latter was measured by the survival $t_{t}$ in compatible normal recipients. However osmotic fragility influenced cell survival since cells with high fragility were rapidly sequestered in the normal spleen. It is suggested that both cell shape and a selective reticuloendothelial blockade in the spleen are important factors in determining the severity of hemolysis in the individual patient.
\end{abstract}

\section{INTRODUCTION}

The anemia in hereditary spherocytosis is rarely severe and almost half the patients present with other symptoms or are discovered in family surveys $(1,2)$. The mild clinical course of this hemolytic anemia is supported by measurements of red cell survival which show modest reductions in life spans which are normally well within the ability of bone marrow compensation. Using the ${ }^{51} \mathrm{Cr}$ red cell survival technique, survival halftimes $\left(t_{1}\right)$ of 8-19 days have been reported for hereditary spherocytes $(1,3-5)$ with the majority falling in the range 10-15 days (normal red cell $t^{t}$ is 28 days). In contrast a rapid destruction of hereditary spherocytes in the normal circulation has been observed in other studies in which ${ }^{51} \mathrm{Cr}$ survivals of $\mathrm{t}_{1}$ of 6 days and 1.9 days have been reported $(4,6)$. These results suggest

Received for publication 4 September 1969 and in revised form 20 November 1969. that the low viability of hereditary spherocytes is even further reduced when these cells are transfused to normal recipients. However hereditary spherocytes are sequestered by the spleen both in affected patients and in normal recipients $(3,4)$ so that the actual mechanism of cell destruction is probably the same in both cases.

In this study the survival of hereditary spherocytes has been measured both in the patient and in normal compatible recipients. In all cases the hereditary spherocytes were destroyed more rapidly in the normal recipient than in the patient's own circulat:on. These results may be viewed as a relative failure of the patient's spleen to sequester his red cells, and the reticuloendothelial blockade has been postulated to explain this splenic inefficiency. The rate of hemolysis in patients with hereditary spherocytosis will thus depend on factors both intrinsic and extrinsic to the red cell while in contrast the survival of hereditary spherocytes in a normal recipient should reflect only the magnitude of the cell defect leading to hemolysis. This cross-survival was taken to estimate the hemolytic tendency of hereditary spherocytes and the $t_{3}$ values were compared with other properties of the cell such as $\mathrm{Na}^{+}$influx and osmotic fragility.

\section{METHODS}

Red cell survivals. These were carried out using the ${ }^{51} \mathrm{Cr}$ technique $(7,8)$ as described previously (9). Survivals were followed until the $t_{3}$ was reached and results were plotted on semi-log paper. All samples were counted together and the count rates were corrected for background and the hematocrit of each sample. No correction was made for elution of ${ }^{51} \mathrm{Cr}$. When sampling at intervals of several minutes was necessary, an indwelling Cournard needle was inserted into the antecubital vein to avoid repeated venepunctures. Normal red cell survivals in seven individuals fell in the range of 26-32 days. ${ }^{1}$ When survivals of spherocytes were measured in normal recipients, they were of the same $A B O$ and $R h$ groups and prior compatibility was established by routine blood-bank cross-matching procedures (polyvinyl pyrrolidine, papain plus indirect Coombs

\footnotetext{
${ }^{1}$ Brodie, G., and B. G. Firkin. Personal communication.
} 
techniques in every case). The nature and risks of the crosssurvival procedure were fully explained to each potential recipient before consent was sought. The consenting recipients were hospital inpatients, both male and female aged between 21 and 78 who were convalescing after orthopedic or opthalmic treatment and were otherwise healthy and had normal hemoglobin, white cell count, and blood films.

Osmotic fragility. This was measured by standard methods (10).

Sodium influx. Venous blood was withdrawn into heparin anticoagulant and the erythrocytes washed three times to remove white cells. A medium of composition $145 \mathrm{~mm} \mathrm{NaCl}$, $5 \mathrm{~mm} \mathrm{KCl}$, and $20 \mathrm{~mm}$ imidazole $\mathrm{Cl}, \mathrm{pH} \mathrm{7.5,} \mathrm{was} \mathrm{used} \mathrm{both}$ for washing and incubation of cell suspensions while $10 \mathrm{~mm}$ glucose was routinely included in the final suspension. Sodium influx was measured from the uptake of radioactivity by cells incubated in this medium containing ${ }^{22} \mathrm{NaCl}$, essentially as described by Glynn (11). Stock ${ }^{22} \mathrm{NaCl}$, obtained from The Radiochemical Centre, Amersham, England, was added to the incubation medium to give a specific activity of about $4000 \mathrm{cpm} / \mu \mathrm{Eq}$ of $\mathrm{Na}^{+}$. Ouabain $(50 \mu \mathrm{M})$ was always included to inhibit extrusion of $\mathrm{Na}^{+}$ions by the active cation pump. The medium was prewarmed for 10 min in a water bath at $37^{\circ} \mathrm{C}$ and the packed washed cells rapidly added by syringe to a final hematocrit of about $15 \%$. The suspension was incubated for $20 \mathrm{~min}$ at $37^{\circ} \mathrm{C}$ with agitation, then cooled for $0.5 \mathrm{~min}$ at $0^{\circ} \mathrm{C}$ and centrifuged for $1 \mathrm{~min}$ in the cold. The supernatant was aspirated and the cells rapidly washed three times in ice cold $0.15 \mathrm{M} \mathrm{NaCl}$ plus $20 \mathrm{~mm}$ imidazole $\mathrm{Cl}, \mathrm{pH} 7.5$, so as to remove extracellular radioactivity. The red cells were hemolyzed in 0.01 $\mathrm{N} \mathrm{NH}_{4} \mathrm{OH}$, counted in a Packard automatic scintillation counter (Packard Instrument Co., Downers Grove, Ill.) and the oxyhemoglobin concentration calculated from the extinction at $540 \mathrm{~m} \mu$ of an appropriate dilution of the hemolyzate. A dilution of the supernatant was also counted; and from the specific activity of extracellular $\mathrm{Na}^{+}$and the mean corpuscular hemoglobin concentration ( $\mathrm{MCHC}$ ), the ${ }^{22} \mathrm{Na}^{+}$influx was calculated.

\section{RESULTS}

Autologous survivals. Measurements of in vivo survivals of hereditary spherocytes were made in 10 patients in whom splenectomy had not been performed. Values for the $\mathrm{t}_{3}$ of $6.3,8.5,10,10,12,12.5,13,16,16$, and 18 days were obtained in different individuals. Surface scanning of organ radioactivity showed a progressive sequestration of spherocytes in the spleen which reached a maximum at or near the $t_{t}$. The shortest survival $t_{t}$ of 6.3 days was obtained in an $89 \mathrm{yr}$ old woman with $6 \mathrm{~cm}$ palpable splenomegaly, $2 \mathrm{~cm}$ hepatomegaly, and a hemoglobin level of $9.7 \mathrm{~g} / 100 \mathrm{ml}$ with $12 \%$ reticulocytes (9).

It was confirmed that hereditary spherocytes survived normally when transfused to a recipient who did not possess a spleen. Spherocytes were transfused from a donor (K. L.) before splenectomy to a recipient who had been splenectomized after past trauma and a survival $\mathrm{t}_{3}$ of 37 days was obtained.

Homologous survivals. The survival of hereditary spherocytes in the circulation is influenced by two major factors, the intrinsic defect in the cell and the interaction of this cell with the spleen. Since splenic hyperplasia involving all cellular elements occurs in hereditary spherocytosis (12), not only will reticuloendothelial activity be altered but also splenic blood flow will be increased. To eliminate any effect of abnormal splenic function or blood flow, the survival curve of hereditary spherocytes was measured in compatible recipients and the $t$ was taken to reflect the intrinsic hemolytic defect of the cell.

If the homologous survival of spherocytes is largely determined by some property of the donor cells, then survival times should be reproducible for the same cells in different normal recipients. Hereditary spherocytes from one donor (D. P.) gave repeated survival $t$ values of $3.1,3.3,3.6$, and 3.8 days in different individuals (Fig. 1). For hereditary spherocytes from another donor (D. McN.) the $t_{1}$ values in normal subjects were 1.5, 2.7, 3.1, and 3.7 days. Although agreement between replicates in this latter case was only fair, they represent the widest scatter of results obtained with any donor. Repeated survival times in the majority of donors with hereditary spherocytosis showed good reproducibility which justifies using the mean value of the $t_{t}$ in two or more normal subjects as an estimate of the intrinsic hemolytic defect of spherocytes from each donor. The sequestration of hereditary spherocytes in the spleen of these normal recipients was confirmed by external organ scanning, and spleen to liver activity ratios of $5: 1$ or more after 1-2 days were not uncommon.

Mean cell age and homologous survival. It is well known that the autologous survival of hereditary spherocytes is increased to almost normal values after splenectomy (13) while the mean cell age must be correspondingly prolonged. The homologous survival of hereditary spherocytes from one patient ( $R$. M.) was measured both before and after his splenectomy to give an indication of the effect of red cell age on cell survival in normal recipients. The survival $t_{t}$ of these cells was 6.0 and 6.5 days in separate recipients (mean 6.2 days) before splenectomy while 3 months after splenectomy the survival $\mathrm{t} t$ had fallen to $4.5,5.2$, and 5.5 days (mean 5.1 days). Although this difference is not great, it does indicate that cell age can influence the homologous survival of hereditary spherocytes although unlike normal red cells, mean age is not the major factor in determining cell life span.

Reticuloendothelial blockade. In seven patients with hereditary spherocytosis and intact spleens it was possible to compare the autologous survivals with survivals of their red cells in compatible recipients. In every case hereditary spherocytes survived longer in the patients circulation than in the normal subjects. In most the 
survival of hereditary spherocytes in normal subjects reached a $\mathrm{t}$ in 2-3 days indicating an approximately 5 -fold greater rate of destruction of spherocytes in normals than in the patient's own circulation. This is well illustrated by the case (G. S.) in Fig. 2 where an autologous survival $t_{3}$ of 12.5 days compares with the mean homologous survival of 1.5 days. The most striking finding was in a patient $(\mathrm{H} . \mathrm{H}$.) whose spherocytes survived with a t of only $12.5 \mathrm{~min}$ in a normal subject although the same cells showed a $t \frac{1}{10}$ days in the patient, a 1000-fold difference in survival times (9). Since an unimpaired reticuloendothelial function may be assumed in the normal recipients, these results suggest a relative failure of splenic destruction of spherocytes in patients with hereditary spherocytosis.

One possible explanation of this splenic inefficiency is that the rate of cell destruction is limited by the maximal catabolic activity of the spleen (14), so that although small numbers of abnormal cells can be rapidly destroyed, the phagocytic ability of the spleen in hereditary spherocytosis is swamped by the large numbers of abnormal cells and their rate of removal is correspondingly slowed. If a limited capacity of the patient's spleen for phagocytosis of red cells is responsible for prolonging their survival relative to the normal subject then the survival of spherocytes should be similarly prolonged when they are transfused from one patient to another.
This was not the case however when hereditary spherocytes from a mother were transfused into her affected son and their survival measured (Table I). The cells were destroyed with a $t$ of 5.4 days and the survival curve lay between the autologous survivals ( $t$ of 10 and 16 days for mother and son) and the survival of the spherocytes in normal recipients (mean $t_{1}$ of 2.7 days for both mother and son). Clearly the recipient's spleen was capable of removing the transfused spherocytes some 3-fold more rapidly than the recipient's own spherocytes ( $t: 16$ days) despite the fact that both donor and recipient spherocytes showed the same susceptibility to destruction in a normal spleen, i.e., both showed the same "hemolytic tendency." Moreover the mother's spherocytes were removed twice as rapidly by the son's spleen as by the mother's spleen.

Although the maximum phagocytic capacity of the spleen may limit the rate of removal of spherocytes in some situations, it cannot explain the lower viability of transfused "foreign" spherocytes when mixed in the circulation with autologous spherocytes. This specificity which the spleen shows towards different spherocytes is equally difficult to explain by an altered proportion of the splenic blood flow which traverses the slow and rapid transit compartment (15). A more likely possibility is that the specificity results from some recognition of different spherocytes by the splenic macrophage.

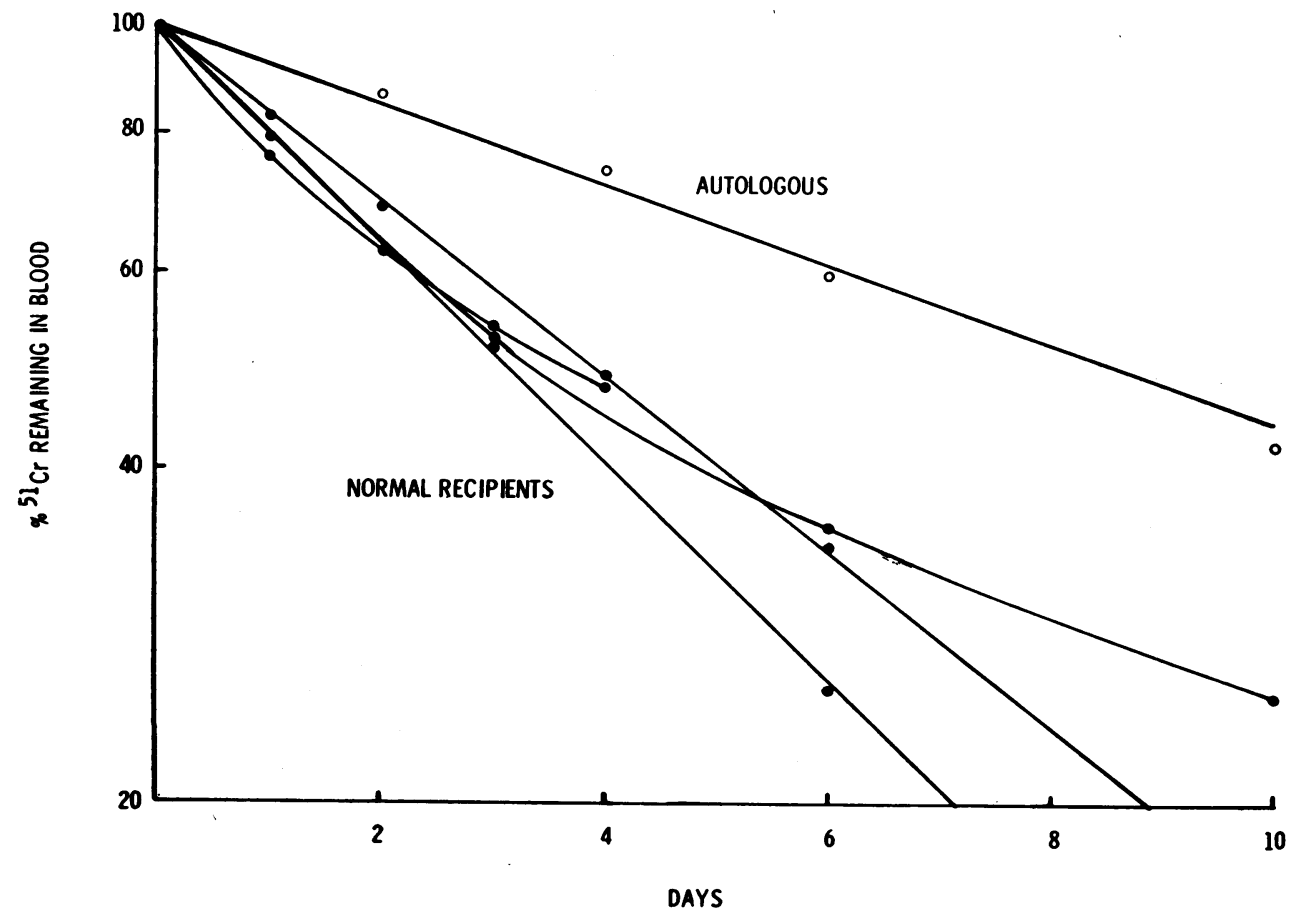

Figure 1 Reproducibility of cell survival of hereditary spherocytes from one donor when transfused to different normal recipients. Mean survival $t_{\frac{1}{2}}$ was 3.5 days in normal recipients. Autologous survival $t_{1}$ was 10 days. 


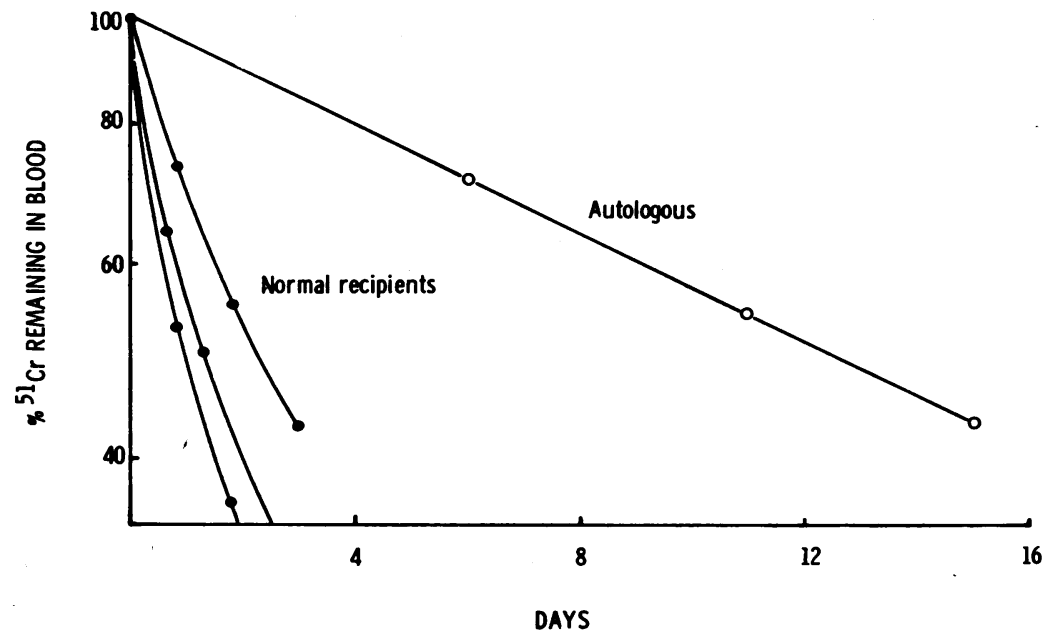

FIGURE 2 Comparison of autologous and homologous in vivo survival of hereditary spherocytes from one donor. Mean survival $t_{1}$ was 1.5 days in normal recipients compared with autologous survival $t_{\frac{1}{2}}$ of 12.5 days.

Such a process would occur at an extracellular or cell membrane level and seems analogous to the specificity observed in some experimental work on reticuloendothelial blockade. If reticuloendothelial blockade does indeed occur in hereditary spherocytosis, it would then be defined as the impairment of the splenic removal of a tagged dose of abnormal red cells which occurs in the presence of large numbers of identical cells in the circulation. Moreover considerable variation could exist in the degree of blockade in different patients. While in one patient $(\mathrm{H} . \mathrm{H}$.) there was a 1000 -fold difference in autologous and homologous survivals, in another patient (E. C.) there was almost no difference since the $t \frac{1}{t}$ was 16 and 14 days for survival of these spherocytes in donor and normals respectively.

Homologous survival and $\mathrm{Na}^{+}$influx. A major aim of this study was to test the hypothesis that the $\mathrm{Na}^{+}$leak is the primary defect in hereditary spherocytosis $(16$, 17). Since hemolysis may be considered the main manifestation of this disease, it might be expected that the magnitude of the $\mathrm{Na}^{+}$leak was simply related to the reduction in red cell life span if the above hypothesis held true, i.e., spherocytes with a high $\mathrm{Na}^{+}$leak would show a short in vivo survival and vice versa. Since the autologous survival of spherocytes is probably complicated by several factors affecting splenic function, the survival $t_{1}$ of spherocytes in compatible normals was taken to measure the intrinsic hemolytic defect of the cell. Cross survivals of spherocytes in normals were performed with 16 patients from 10 unrelated families with hereditary spherocytosis. For most patients two or more survivals were performed in different normals although in three cases only a single survival was possible. The mean $t_{3}$ of the homologous survivals for each patient was then compared with the $\mathrm{Na}^{+}$influx into spherocytes from the same patient.

No correlation could be obtained between in vivo survival $t_{t}$ and the size of the $\mathrm{Na}^{+}$leak, as measured by $\mathrm{Na}^{+}$influx (Fig. 3). Although there is little doubt that the $\mathrm{Na}^{+}$leak is an inherited defect in the red cell in this disease, the present result argues against any pathogenetic role of the $\mathrm{Na}^{+}$leak in hemolysis. Of particular interest was the finding that hereditary spherocytes with a high $\mathrm{Na}^{+}$leak showed a relatively long in vivo survival in normal recipients. The mean $t_{1}$ values for four patients with the highest $\mathrm{Na}^{+}$influxes were $5.1,6.5,10.2$, and 12 days whereas the survivals for nearly all the other patients were less than a $t_{1}$ of 4 days (Fig. 3).

Survivals and osmotic fragility. The importance of osmotic fragility in determining the viability of hereditary spherocytes has long been suspected and now has strong experimental support (6). It was therefore of interest to compare the median corpuscular fragility of red cells from individual patients with the mean homologous survival $t$ for the same cells. Most patients pos-

TABLE I

In Vivo Survival of Hereditary Spherocytes

\begin{tabular}{lccc}
\hline & $\begin{array}{c}\text { In normal } \\
\text { recipients } \\
\text { (O positive) }\end{array}$ & $\begin{array}{c}\text { Mother's } \\
\text { cells in son's } \\
\text { circulation }\end{array}$ & $\begin{array}{c}\text { Autol- } \\
\text { ogous } \\
\text { survival }\end{array}$ \\
\hline Mother (O positive) & $\begin{array}{c}3.3,3.0,1.8^{t_{\text {t }} \text { (days) }} \\
\text { Mean } 2.7\end{array}$ & - & 10 \\
Son (O positive) & $\begin{array}{c}2.5,2.9 \\
\text { Mean } 2.7\end{array}$ & 5.4 & 16 \\
& & & \\
\hline
\end{tabular}

Red Cell Survival in Hereditary Spherocytosis 
sessed hereditary spherocytes with a median corpuscular fragility between 0.46 and $0.54 \% \mathrm{NaCl}$ and in this group there was no clear relation between fragility and survival $t$. Three patients with osmotic fragilities outside this range gave more significant results (Fig. 4). Two were brothers with hereditary spherocytosis and had very high median corpuscular fragilities of 0.68 and $0.57 \% \mathrm{NaCl}$ and dramatically shortened red cell survivals in normal recipients of $t_{1}$ of 12.5 and $90 \mathrm{~min}$ respectively (9). In contrast another patient (E. C.) with a barely raised osmotic fragility (median corpuscular fragility $0.455 \% \mathrm{NaCl}$ ) had spherocytes with the longest survival yet found in a normal ( $t$ t 14 days). Although more data are required to clarify the exact relation between osmotic fragility and survival $t_{t}$, there seems little doubt that high osmotic fragility of spherocytes is associated with their rapid sequestration and destruction in a normal spleen.

Osmotic fragility and $\mathrm{Na}^{+}$leak. No correlation was observed between the magnitude of the $\mathrm{Na}^{+}$influx and the median corpuscular fragility for hereditary spherocytes from nine patients, which confirms the conclusions of Bertles (18).

\section{DISCUSSION}

These studies demonstrate that the viability of hereditary spherocytes is invariably lower in a normal recipient than in the donor's own circulation. Although several factors may operate to produce this difference, it seems likely that reticuloendothelial blockade of the patient's spleen makes at least some contribution. The phenomenon of reticuloendothelial blockade has been known for years and describes the depressed rate of clearance of a tracer dose of colloid after intravenous injection of a large blockading dose of colloid. This blockade is often quite specific and will only operate when the test material has the same surface characteristics as the blockading agent (19-21). Moreover in some studies retiouloendothelial blockade seemed to be dependent on the persistence in the circulation of the original blockading dose of colloid $(20,22)$. Many studies have now demonstrated that blockade does not simply result from physical saturation of macrophages by the injected colloid. Two mechanisms of blockade have been proposed, the saturation of membrane binding sites and the depletion of plasma opsonins, and both mechanisms have support from work on experimental animals and perfused organs (23).

Evidence for a reticuloendothelial blockade in hereditary spherocytosis is circumstantial and rests on two main lines of information. Firstly, the survival of spherocytes in vivo is always longer in the patient's circulation than in a normal compatible recipient. Although minor differences in the survival times could be explained by a different partition of splenic blood flow between slow and rapid transit compartments (15), this explanation is less likely for the gross differences in survival times obtained with one patient (H.H.) whose

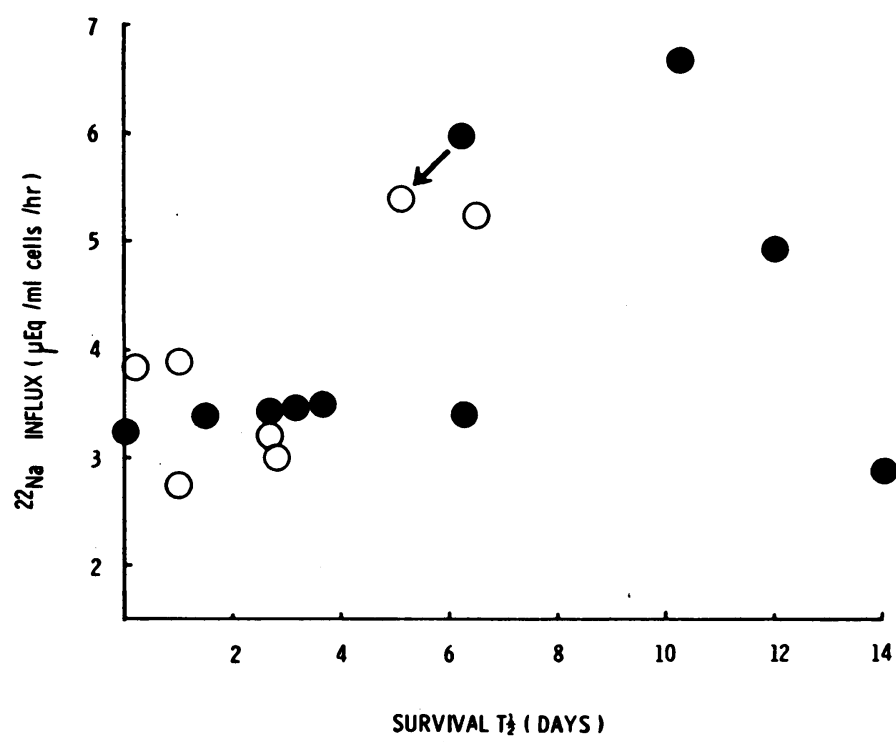

FIGURE 3 Comparison of ${ }^{22} \mathrm{Na}$ influx and mean homologous survivals of hereditary spherocytes from 16 patients. Closed circles represent patients with intact spleens, while open circles represent patients in whom the spleen has been removed. The arrow indicates the two points obtained from one patient before and after his splenectomy. 


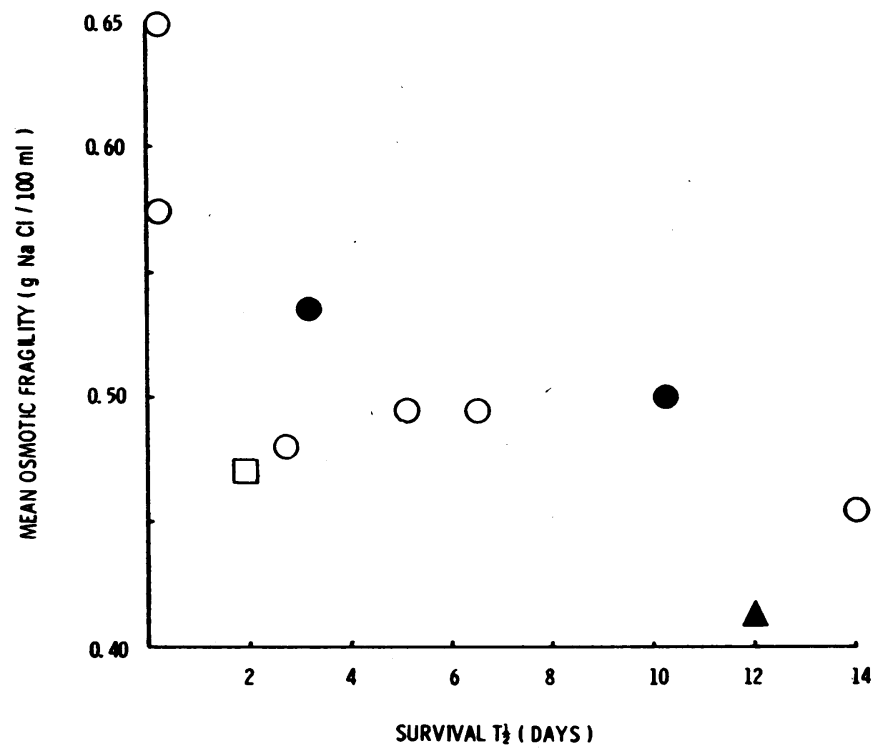

FIGURE 4 Comparison of mean osmotic fragility and mean homologous survivals of hereditary spherocytes. The square point corresponds to hereditary spherocytes described by Cooper and Jandl (6), while the triangle corresponds to the same cells circulating in a recipient with obstructive jaundice. The closed circles represent patients with intact spleens; open circles represent patients in whom the spleen has been removed.

cells survived with $\mathrm{t}_{1}$ of $12.5 \mathrm{~min}$ in a normal and 10 days in himself, a 1000 -fold difference in survival times. Although almost complete shunting of blood through the rapid transit compartment of the spleen in H.H. could be postulated, the result of a single cross-survival of compatible spherocytes in H.H. does not support this postulate. Spherocytes from a donor (D.McN.) were transfused into H.H. and survived with a t 5.6 days. The same spherocytes (from D.McN.) survived with a mean $t_{1}$ of 2.8 days in normal recipients. This result suggests that if any rapid shunting of blood occurs through the spleen of H.H. it was not complete and therefore could not fully explain the 1000 -fold difference in survival times mentioned above. A partial paralysis of the normal splenic sequestration of hereditary spherocytes must have existed and prolonged red cell life span to a value compatible with marrow compensation. The observation of Howell-Jolly bodies in spherocytes from this patient (H.H.) before surgery may possibly be related to gross reticuloendothelial blockade and subsequent reduction in the usual "pitting" function of the spleen.

A second finding which supports the concept of reticuloendothelial blockade is that "foreign" spherocytes, even though compatible, are cleared more rapidly than "self" spherocytes by the recipient's spleen. Intracellular digestion of red cells cannot provide sufficient specificity to distinguish between "foreign" and "self" spherocytes so the discrimination shown by the spleen towards these two different spherocytes probably resides at an extracellular level. Whether recognition of cells by the spleen involves their coating with plasma opsonins or combination with specific binding sites on the macrophage is not clear although both mechanisms seem possible in reticuloendothelial blockade (23).

Clearly reticuloendothelial blockade would be a favorable development in patients with hereditary spherocytosis since the severity of hemolysis is reduced with mitigation of the degree of anemia. Whether reticuloendothelial blockade occurs in other hemolytic anemias is not known although the relatively benign occurrence of homozygous sickle cell anemia in some adults implicates some unknown factor in this hemolytic process (24). Hereditary elliptocytosis may show inexplicable variations in hemolytic rate between affected members of the same family; and since all members share the same abnormal gene, an unknown factor is again implicated in hemolysis $(25,26)$.

An important finding in this study was that the magnitude of the $\mathrm{Na}^{+}$leak was not proportional to the reduction in viability of spherocytes, as measured by the in vivo survival of these cells in normal compatible recipients so as to avoid any effects of impaired splenic function. Although the $\mathrm{Na}^{+}$leak is established as an in- 
herited manifestation of the underlying mutation, this result does not support the hypothesis that the $\mathrm{Na}^{+}$leak is the primary defect in this disease. It appears rather that the mutation in hereditary spherocytosis affects multiple functions of the cell membrane involved in $\mathrm{Na}^{+}$ turnover, lipid stability, and cell survival and that spherocytes with the largest $\mathrm{Na}^{+}$leak tended to have not the shortest but the longest homologous survivals.

Cell shape or some other property reflected in the high osmotic fragility does seem to be a major determinant of cell survival since spherocytes with a high osmotic fragility had a short in vivo survival while one patient with a near normal osmotic fragility had a relatively long cell survival. Moreover Cooper and Jandl (6) have shown that the progressive decrease in osmotic fragility of hereditary spherocytes in the circulation of patients with obstructive jaundice is associated with a parallel increase in the survival of these cells. Numerous factors both intrinsic to the cell, such as shape and viscosity $(27,28)$, and extrinsic factors which may include reticuloendothelial blockade thus seem important in determining the survival of spherocytes in the patient. The degree of anemia must depend on the balance between these factors. It is therefore not surprising that wide variations are found in the clinical severity of this disease.

\section{ACKNOWLEDGMENTS}

I am grateful to Professor B. G. Firkin for his help and encouragement throughout this work. I thank Dr. G. Brodie for his comments on the manuscript and the Huish, Lowe, McMillan, and Morris families for their generous cooperation.

This work was supported by a grant from the National Health and Medical Research Council.

\section{REFERENCES}

1. Dacie, J. V. 1960. The congenital anaemias. In The Haemolytic Anaemias. Part I. 2nd edition. Churchill (J. \& A.) Ltd., London. 88, 106.

2. Krueger, H. C., and E. O. Burgert. 1966. Hereditary spherocytosis in 100 children. Mayo Clin. Proc. 41: 821.

3. Jandl, J. H., M. S. Greenberg, R. H. Yonemoto, and W. B. Castle. 1956. Clinical determination of the sites of red cell sequestration in hemolytic anemias. J. Clin. Invest. 35 : 842.

4. Schloesser, L. L., D. R. Korst, D. V. Clatanoff, and R. F. Schilling. 1957. Radioactivity over the spleen and liver following the transfusion of chromium "labelled erythrocytes in hemolytic anemia. J. Clin. Invest. 36: 1470.

5. Kinlough, R. L., R. C. Bennett, and H. Lander. 1966. The place of splenectomy in haematological disorders: the value of ${ }^{\circ} \mathrm{Cr}$ techniques. Med. J. Aust. 2: 1022.

6. Cooper, R. A., and J. H. Jandl. 1969. The role of membrane lipids in the survival of red cells in hereditary spherocytosis. J. Clin. Invest. 48: 736.
7. Read, R. C., G. W. Wilson, and F. H. Gardner. 1954. The use of radioactive sodium chromate to evaluate the life-span of the red blood cell in health and certain hematologic disorders. Amer. J. Med. Sci. 228: 40.

8. Mollison, P. L., and N. Veall. 1955. The use of the isotope ${ }^{51} \mathrm{Cr}$ as a label for red cells. Brit. J. Haematol. $1: 62$.

9. Wiley, J. S., and B. G. Firkin. An unusual variant of hereditary spherocytosis. Amer. J. Med. In press.

10. Dacie, J. V., and S. M. Lewis. 1963. Practical Haematology. 3rd edition. Churchill (J. \& A.) Ltd., London. 136.

11. Glynn, I. M. 1956. Sodium and potassium movements in human red cells. J. Physiol. (London). 134: 278.

12. Jandl, J. H., N. M. Files, S. B. Barnett, and R. A. MacDonald. 1965. Proliferative response of the spleen and liver to hemolysis. J. Exp. Med. 122: 299.

13. Chapman, R. G. 1968. Red cell life span after splenectomy in hereditary spherocytosis. J. Clin. Invest. 47: 2263.

14. Mollison, P. L. 1962. The reticulo-endothelial system and red cell destruction. Proc. Roy. Soc. Med. 55: 915.

15. Jandl, J. H., and R. H. Aster. 1967. Increased splenic pooling and the pathogenesis of hypersplenism. Amer. J. Med. Sci. 253: 383 .

16. Jacob, H. S., and J. H. Jand1. 1964. Increased cell membrane permeability in the pathogenesis of hereditary spherocytosis. J. Clin. Invest. 43: 1704.

17. Jacob, H. S. 1967. Membrane lipid depletion in hyperpermeable red blood cells: its role in the genesis of spherocytes in hereditary spherocytosis. J. Clin. Invest. 46: 2083.

18. Bertles, J. F. 1957. Sodium transport across the surface membrane of red blood cells in hereditary spherocytosis. J. Clin. Invest. $36: 816$.

19. Wagner, H. N., and M. Ilio. 1964. Studies of reticuloendothelial system (RES). III. Blockade of the RES in man. J. Clin. Invest. 43: 1525.

20. Koenig, M. G., R. M. Heyssel, M. A. Melly, and D. E. Rogers. 1965. The dynamics of reticulo-endothelial blockade. J. Exp. Med. 122: 117.

21. Schapiro, R. L., W. J. MacIntyre, and D. I. Schapiro. 1966. The effect of homologous and heterologous carrier on the clearance of colloidal material by the reticuloendothelial system. J. Lab. Clin. Med. 68: 286.

22. Drutz, D. J., M. G. Koenig, and D. E. Rogers. 1967. Further observations on the mechanism of reticuloendothelial blockade. J. Exp. Med. 126: 1087.

23. Nelson, D. S. 1969. In Macrophages and Immunity. North Holland Publishing Co., Amsterdam. 126.

24. Serjeant, G. R., R. Richards, P. R. H. Barbor, and P. F. Milner. 1968. Relatively benign sickle-cell anaemia in 60 patients aged over 30 in the West Indies. Brit. Med. J. $3: 86$.

25. Jensson, O., Th. Jonasson, and O. Olafsson. 1967. Hereditary elliptocytosis in Iceland. Brit. J. Haematol. 13: 844 .

26. Pearson, H. A. 1968. The genetic basis of hereditary elliptocytosis with hemolysis. Blood. 32: 972.

27. Jandl, J. H., R. L. Simmons, and W. B. Castle. 1961. Red cell filtration and the pathogenesis of certain hemolytic anemias. Blood. 18: 133.

28. Weed, R. I., P. L. LaCelle, and E. W. Merrill. 1969. Metabolic dependence of red cell deformability. J. Clin. Invest. 48: 795 . 